\title{
Connectivism in Science Education with Emphasis on International Collaboration
}

\author{
Eva Trnova and Josef Trna
}

Department od Physics, Faculty of Education,

Masaryk University, Porici 7, 60300 Brno, Czech Republic, EU

\begin{abstract}
The study presents the results of design-based research on the influence of connectivism on science education, with the emphasis on an international collaboration among/between teachers and students from different countries. Science and technology education is a very important part of culture as a knowledge background of society. Very fast ICT development strongly influences education. The pedagogical theory of connectivism was born as a response to this ICT development. Thus a need occurred to examine these connectivistic influences on science and technology education. This study presents a design-based research which is focussed on the following issues: identification of connectivistic factors and their influence on science education; creation of connectivistic educational methods; implementation of connectivistic educational methods into teaching/learning and teacher's training. These methods were created within the frame of collaborative action research based on ICT which can be used as a vehicle for international collaboration with effective exploitation of ICT. The collaborative action research based on ICT was carried out by two collaborating teachers and their students in the Czech Republic and in Portugal. Concrete scenarios and strategic planning of the collaborative connectivistic teaching/learning are presented on the topic photosynthesis. Our design-based research results verify that implementation of connectivism in science education is reality. We identify the set of connectivistic factors which influence science education: selection of topic, selection of students, use of Information and Communication Technologies (ICT), collaboration schedule and elaboration of materials for teaching and learning. Connectivistic educational methods in science education are also presented. Connectivistic teaching/learning methods have a very positive influence on science education. This connectivistic approach can contribute to reducing the gap between educational research and school practice. It will be important to implement our research results into pre-service and especially in-service science teacher training.
\end{abstract}

Keywords: Information and Communication Technologies (ICT), Development Strongly Influences, Collaboration Schedule, Information Revolution, Connectivistic Approach

\section{INTRODUCTION}

Science and technology education is a very important part of culture as a knowledge background of society. However, there has been a decrease in the interest of science and technology education in the past decades. This negative situation has many causes and factors. Among these factors belong changes in the attitude of students to education, post-modernist diversion from science and technology education, tendency to perceive education narrowly as a commodity in the strong economic sense, information revolution and fast development of ICT applications.

Teachers need to be equipped with new competences and innovated professional skills. They have to be able to implement new contents and namely to

Corresponding Author: Eva Trnova, Department of Physics, Faculty of Education, Masaryk University, Porici 7, 60300 Brno, Czech Republic, EU 
gain new methods and instruments of innovative educational technologies. The teacher's training necessarily becomes a lifelong process. Teachers are not satisfied with only ready prepared instructions on how to change their teaching but they need to understand the scientific reasoning of these innovated educational methods and instruments. Thus research-based teacher training has been established as a new dimension of the professional preparation of teachers.

The implementation of design-based research and connectivism is an important part of innovative science educational technologies. These phenomena are presented in our study. Behaviourism, cognitivism and constructivism are the three main teaching/learning pedagogical theories still used in science education. Very fast ICT development strongly influences education. ICT technology has reorganized our life, communication and also how we learn and teach.

The new pedagogical theory of connectivism was born as a response to this invasive ICT development. Siemens (2005) laid down the foundations of connectivism theory. According to Siemens (2005) "learning (defined as actionable knowledge) can reside outside of ourselves (within an organization or a database), is focused on connecting specialized information sets and the connections that enable us to learn more are more important than our current state of knowing." Siemens established the first principles of connectivism (Siemens, 2005):

- Learning and knowledge rests in diversity of opinions

- Learning is a process of connecting specialized nodes or information sources

- Learning may reside in non-human appliances

- Capacity to know more is more critical than what is currently known

- Nurturing and maintaining connections is needed to facilitate continual learning

- Ability to see connections between fields, ideas and concepts is a core skill

- Currency (accurate, up-to-date knowledge) is the intent of all connectivistic learning activities

- Decision-making is it a learning process. Choosing what to learn and the meaning of incoming information is seen through the lens of a shifting reality. While there is a right answer now, it may be wrong tomorrow due to alterations in the information climate affecting the decision

Thus a need occurred to examine possible connectivistic influences on science and technology education. Our research is focussed on the following issues: identification of connectivistic factors and their influence on science and technology education; creation of connectivistic educational methods; implementation of connectivistic educational methods into teaching/learning and teacher's training.

\section{MATERIALS AND METHODS}

\subsection{Design-Based Research}

Design-based research is a development research. This research differs from other types of researches. Comparison between the design-based research and empirical research presents scheme which was compiled by Reeves (2006) (Fig. 1).

The core of design-based research is orientation to the creation of a new product. This research offers solutions to problems that so far have been only solved partially and relevant instruments and methods (Jarvinen, 2004). The main advantage of the design-based research is its close connection with educational practice. Many results of the other researches are considered as separate from practice and are not understood by teachers. The basic principle and advantage of the design-based research is the close cooperation between researchers and teachers, which is a prerequisite of direct use of the outputs of the research in everyday practice.

The above reasons led us to use design-based research to address the issue of the implementation of connectivism into science and technology education.

\subsection{Collaborative Action Research Based on ICT}

Action research represents educational research whose main identifying characteristic is the requirements of teachers for organized reflective inquiry into classroom instruction. Action research is a process designed to empower all participants in the educational process (students, teachers and other parties) with the means to improve the practices conducted within the educational experience. All participants are active members of the research process (Hopkins, 2008).

Sometimes action research is known by other terms such as participatory research, collaborative inquiry, emancipator research, action learning and contextual action research but all have the same basis. This method is "inevitably threatening to the traditional professional cultures of both teachers and academic teacher educators. As a form of mutual professional learning it requires a transformation of both school and academic cultures" (Elliot, 1991). 

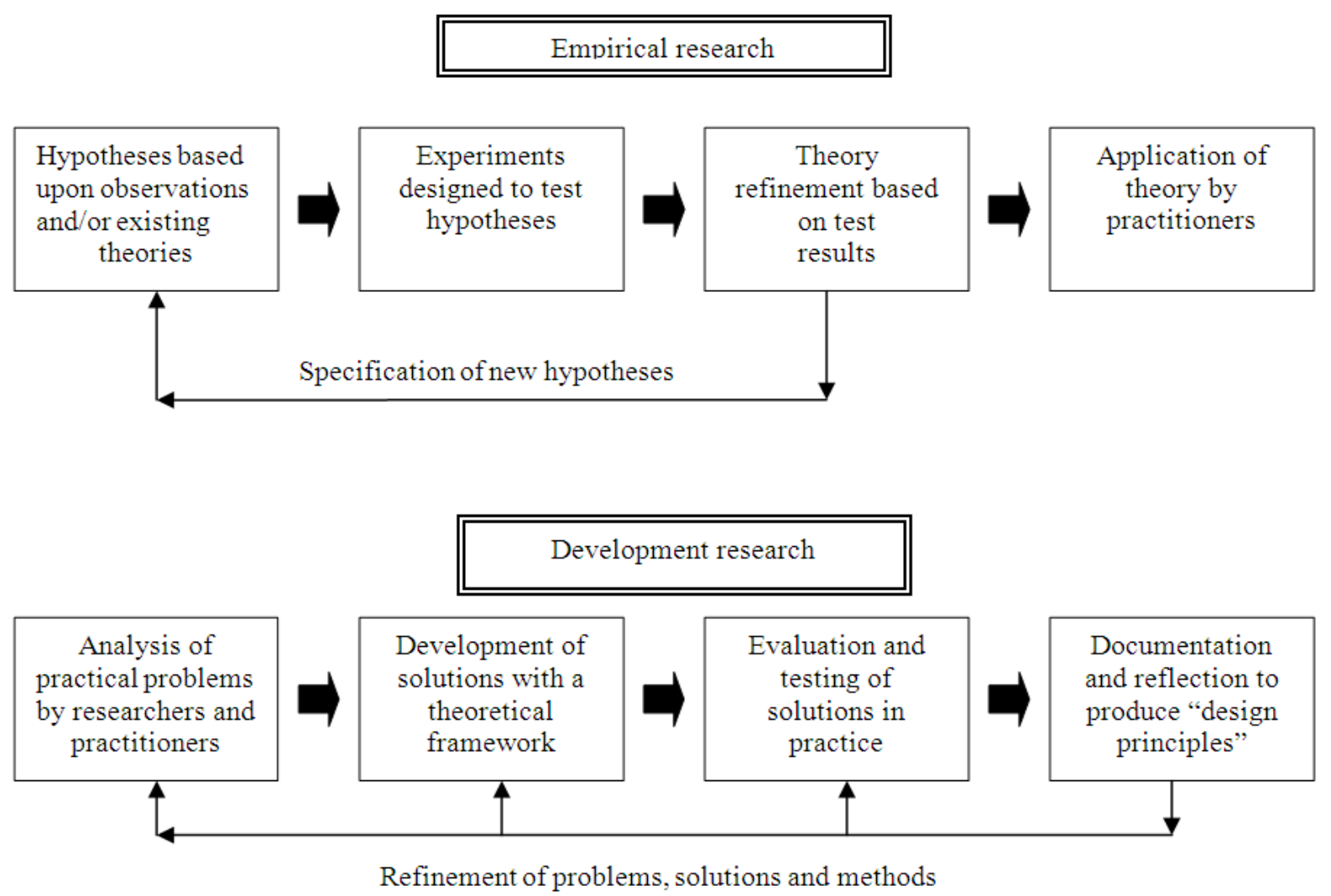

Fig. 1. Empirical and development researches

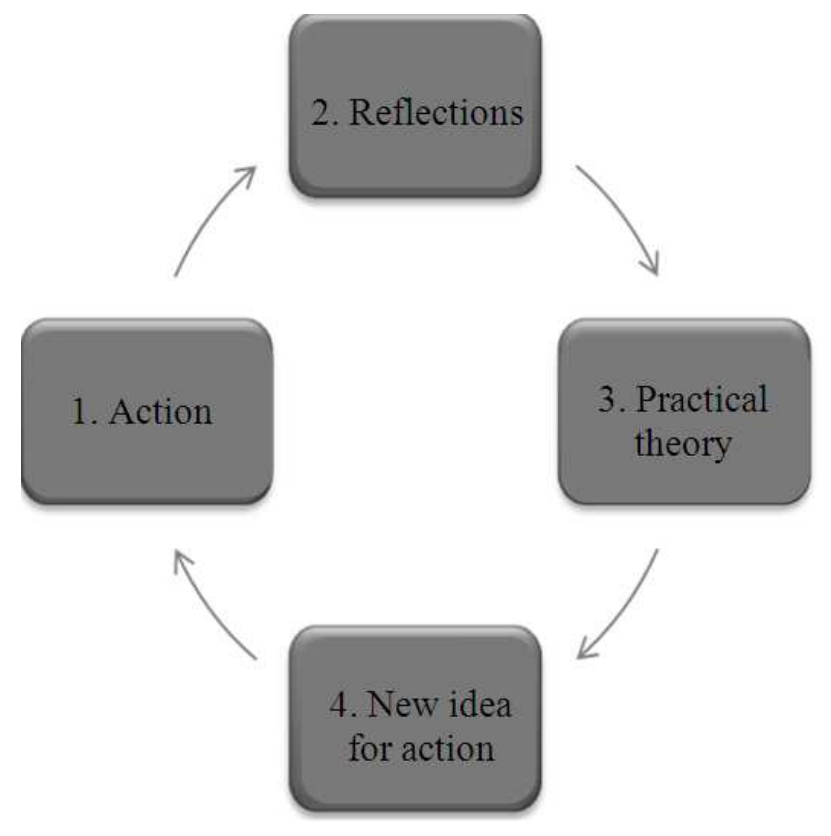

Fig. 2. Diagram of action research 
The concise simple characterization of action research is "learning by doing": To identify a problem, to do something to resolve it, to see how successful their efforts were and if not satisfied, to try again. The diagram (Fig. 2) clearly describes this process (Elliot, 1991).

The action is the basis of this continuous research cycle. A plan of action based on the information from the data collection and review of current literature, will allow the teacher to make a change and to study that change. It is necessary to determine which action is responsible for the outcome. So, it is crucial to develop a time-line to gather evidence (data) to be collected. Evidence includes such methods and tools as questionnaires/surveys, observations (video or written notes), collaborations (video or audio tapes of meetings, peer coaching) interviews, tests, students' portfolios. Action is central in the teachers' activity, but reflection should be in the core of their professional development. From the interaction between practice and reflection (Fig. 2) in action research, theory informs practice and practice improves theory in a continuous cycle. The ensuing practical applications that follow are subjected to further analysis, in a transformative cycle that continuously alternates emphasis between theory and practice.

Our innovative idea is to use action research in a web-based environment realised through international collaboration (Trna and Trnova, 2010). Action research is mainly used by one teacher in one class, but can be explored in modified conditions for example by two collaborating teachers, working on-line in two classrooms, in two different countries, using English in addition to home languages and on-line instruction by use of ICT. By undertaking a number of research cycle phases we can upgrade the outcomes from the action research with respect to the ultimate design of the collaborative action research. An important aspect of this approach is that participants in a collaborative action research are co-researchers. The principle of collaborative co-researches presupposes that each participant's ideas are equally significant as a potential resource for creating interpretive categories for analysis, as negotiated among the participants.

\subsection{Research Questions}

The research methodology we used is action research in a web-based environment realised through the international collaboration of science teachers. We call this teaching/learning method "ICT-based collaborative action research" (Trna and Trnova, 2010). Teachers-researchers in a collaborative action research are co-researchers.

The "action" factor of our action research is collaboration among teachers and students from two countries: Portugal and the Czech Republic. The aim was to upgrade teaching and learning using motivational methods and innovative school experimentation.

Design-based research as development research was used as a meta-methodology. The first step of this design-based research is: Analysis of practical problems by researchers and practitioners (Fig. 1). We identify in the research field Implementation of connectivism in science and technology education with emphasis on international collaboration following special problems:

- Identification of connectivistic factors and their influence on science education

- Creation of connectivistic educational methods

- Implementation of connectivistic educational methods into teaching/learning and teacher's training

- This study presents the first results of our research focussed on connectivistic international collaboration

A wide field of above mentioned issues was narrowed down in this first design-based research stage (Fig. 1) to the research question:

Which connectivistic factors is it possible to identify in collaborative action research based on ICT? The second step of the design-based research is: Development of Solutions with a Theoretical Framework (Fig. 1)

This second design-based research stage brought us the research question:

Which connectivistic educational methods are effective for the implementation of collaborative action research based on ICT?

The third and fourth steps of the design-based research are: Evaluation and Testing of Solutions in Practice and Documentation and Reflection to Produce "Design Principles" (Fig. 1). These two stages produced common results in the form of "Design principles".

\section{RESULTS AND DISCUSSION}

\subsection{Connectivistic Factors}

The first research question connected to the first design-based research stage is:

Which connectivistic factors is it possible to identify in collaborative action research based on ICT?

We identified by the use of factor analysis the following connectivistic factors:

- Selection of topic 
- Selection of students

- Use of Information and Communication Technologies (ICT)

- Collaboration schedule

- Elaboration of materials for teaching and learning

The example of one of these factors is briefly presented:

(2) Selection of students: The main conditions for selection of students are comparable age and ability. They need to be approximately the same age because of the requirement for collaboration. Students need also to have a reasonable capacity to both communicate in English and use ICT and to be able to understand teaching content (Table 1).

\subsection{Connectivistic Methods}

The second design-based research stage brought us the research question:

Which connectivistic educational methods are effective for the implementation of collaborative action research based on ICT?

We identified the following connectivistic teaching/learning methods:

- Communication with colleagues in the other country (new information, applications of new knowledge from abroad, new personal contacts)

- Exchange of experiences between teachers (teaching methods) by comparing curricular material (textbooks, learning tasks, experimentation)

- Inserting of new educational methods based on research by teacher's application of action research monitored by science educational experts

- Acquisition of new subject knowledge and skills from abroad

- Development of collaboration competencies between teachers and among students (needed more than usual communication)

- Team collaboration among teachers inside the partner schools (support with ICT, English, organisation of lessons)

- Team collaboration among students within the partner schools (support with ICT, organisation of lessons)

An example of these methods is briefly presented:

(4) Acquisition of new subject knowledge and skills: Information, experiments and learning tasks which are missing in the Czech biology curriculum (Table 2).
Table 1. Selection of students

\begin{tabular}{|c|c|c|}
\hline Characteristics & $\begin{array}{l}\text { The Czech } \\
\text { students }\end{array}$ & $\begin{array}{l}\text { The portuguese } \\
\text { students }\end{array}$ \\
\hline $\begin{array}{l}\text { Age } \\
\text { Position at school } \\
\text { III } \\
\text { grammar school }\end{array}$ & $\begin{array}{l}15-16 \text { years } \\
\text { first year of }\end{array}$ & $\begin{array}{l}15-16 \text { years } \\
\text { first year of level }\end{array}$ \\
\hline $\begin{array}{l}\text { Ability to } \\
\text { communicate }\end{array}$ & English & English \\
\hline Ability to use ICT & $\begin{array}{l}\text { PC, Skype, } \\
\text { ICQ, e-mail }\end{array}$ & $\begin{array}{l}\text { PC, Skype, } \\
\text { ICQ, e-mail }\end{array}$ \\
\hline
\end{tabular}

Table 2.New information for Czech teacher gained from worksheet relating to "How do autotrophic beings get the matter responsible for their growth

\begin{tabular}{|c|c|}
\hline New experiment & Van Helmont experiment \\
\hline $\begin{array}{l}\text { New interesting } \\
\text { learning task }\end{array}$ & $\begin{array}{l}\text { "Mention some of the } \\
\text { factors that could explain the } \\
\text { differences observed in Northern } \\
\text { and the Southern Hemispheres." }\end{array}$ \\
\hline New information & $\begin{array}{l}\text { Data about the amount of } \\
\mathrm{CO}_{2} \text { absorption } 3-4 \text { times } \\
\text { higher in eucalyptus forests in Portugal. } \\
\text { Primary Production is the } \\
\text { amount of organic matter that is } \\
\text { produced by autotrophic beings from } \\
\text { solar energy photosynthetic } \\
\text { organisms) or chemical energy } \\
\text { Gross primary production } \\
\mathrm{PPB} \text { ) is conversion rate } \\
\text { (of } \mathrm{CO}_{2} \text { into organic carbon } \\
\text { per unit area The Net Primary } \\
\text { Production (PPL) is all the energy } \\
\text { that producers store from the photosynthesis } \\
\text { (PPB) minus what they spend } \\
\text { on respiration (R): PPL = PPB-R } \\
\text { The efficiency of photosynthesis is } \\
\text { converted to radiation } \\
\text { incident to PPL divided by the total incident } \\
\text { radiation }\end{array}$ \\
\hline
\end{tabular}

Table 3. Questionnaire results 1

\begin{tabular}{ll}
\hline $\begin{array}{l}\text { Responses by Portuguese/Czech students } \\
\text { (from the questionnaire for students): }\end{array}$ \\
$\begin{array}{l}\text { Do you believe that the online } \\
\text { environment influenced }\end{array}$ \\
your teacher's performance? & $\mathrm{N}=27 / 21$ \\
\hline Yes & $52 \% / 67 \%$ \\
No & $48 \% / 33 \%$ \\
\hline
\end{tabular}

Table 4. Questionnaire results 2

\begin{tabular}{ll}
\hline $\begin{array}{l}\text { Responses by Portuguese/Czech students } \\
\text { (from the questionnaire for students): }\end{array}$ & \\
$\begin{array}{l}\text { Do you believe that the online environment } \\
\text { influenced your performance and learning? }\end{array}$ & $\mathrm{N}=27 / 21$ \\
\hline Yes & $89 \% / 90 \%$ \\
No & $11 \% / 10 \%$ \\
\hline
\end{tabular}


Table 5. Questionnaire results 3

Responses by Portuguese/Czech students

(from the questionnaire for students):

During the topic "Obtaining matter

by autotrophic beings: Photosynthesis and

Chemosynthesis" in partnership

with Portuguese colleagues in an

online environment, your

with Portuguese colleagues in an

\begin{tabular}{|c|c|c|c|c|c|}
\hline $\mathrm{N}=27 / 21$ & $\begin{array}{l}\text { Diagree } \\
(\%)\end{array}$ & $\begin{array}{l}\text { Partially } \\
\text { agree }(\%)\end{array}$ & $\begin{array}{c}\text { Agree } \\
(\%)\end{array}$ & $\begin{array}{l}\text { Strongly } \\
\text { agree }(\%)\end{array}$ & $\begin{array}{l}\text { No } \\
\text { opinion (\%) }\end{array}$ \\
\hline \multirow[t]{2}{*}{ Anxiety } & 4 & 63 & 33 & 0 & 0 \\
\hline & 85 & 10 & 0 & 0 & 5 \\
\hline \multirow[t]{2}{*}{ Confusion } & 52 & 37 & 11 & 0 & 0 \\
\hline & 52 & 33 & 5 & 0 & 10 \\
\hline \multirow[t]{2}{*}{ Perplexity } & 44 & 37 & 11 & 0 & 8 \\
\hline & 42 & 29 & 19 & 5 & 5 \\
\hline \multirow[t]{2}{*}{ Challenge } & 0 & 26 & 26 & 48 & 0 \\
\hline & 5 & 10 & 47 & 24 & 14 \\
\hline \multirow[t]{2}{*}{ Enthusiasm } & 0 & 8 & 44 & 48 & 0 \\
\hline & 5 & 14 & 43 & 33 & 5 \\
\hline \multirow[t]{2}{*}{ Indifference } & 88 & 8 & 4 & 0 & 0 \\
\hline & 42 & 29 & 14 & 5 & 10 \\
\hline
\end{tabular}

Examples of evaluation and testing in practice are briefly presented

\subsection{Connectivistic Principles}

The third and fourth steps of the design-based research are: Evaluation and Testing of Solutions in Practice and Documentation and Reflection to Produce "Design Principles" (Fig. 1). These two stages produced common results in the form of "connectivistic principles" of the use of collaborative action research based on ICT:

- International collaboration based on ICT is effective motivational connectivistic method for students and teachers (by communication with colleagues in other country, new information, applications of new knowledge from abroad, new personal contacts)

- International collaboration based on ICT is effective connectivistic educational method for exchange of experiences between teachers (teaching methods) by comparing curricular material (textbooks, learning tasks, experimentation)

- International collaboration based on ICT is effective connectivistic educational method for exchange of experiences between students and creation of their friendship nets

- International collaboration based on ICT is effective connectivistic educational method for acquisition of new subject knowledge and skills (e.g., Van Helmont experiment)
- International collaboration based on ICT is effective connectivistic educational method for gaining of collaboration competencies between teachers and among students

- International collaboration based on ICT is effective connectivistic educational method for team collaboration between/among teachers inside the partner schools

- International collaboration based on ICT is effective connectivistic educational method for team collaboration between/among students within the partner schools

Students completed a questionnaire that focused on their reflections on this innovative bilateral connectivistic collaboration (Trna and Trnova, 2010). Their answers indicate very high levels of both motivation and engagement with the educational process; they learnt a great deal (Table 3-5). Our rudimentary design-based research results verify that implementation of connectivism in science and technology education with emphasis on international collaboration is reality. We identify the set of connectivistic factors which influence science and technology education. Analysis of the collaborative action research based on ICT confirms the existence of appropriate connectivistic educational methods which are effective in science education.

All our research methods and tools used such as tests, questionnaires, observations, interviews, students' and teachers' portfolios and video recordings, indicate that students learnt with interest and their knowledge and skills are better than would be expected using classic methods.

\section{CONCLUSION}

The international dimension of connectivistic science education provides a good opportunity for the development and dissemination of ideas and curricular materials among teachers by use of ICT. A web-based environment can be a very effective educational technology for science teachers' and students' collaboration leading to upgrading of science education. Connectivistic teaching/learning methods and instruments have a very positive influence on groups of both students and teachers-researchers. This connectivistic approach can contribute to reducing the gap between educational research and school practice (Hammersley, 2002). We have implemented our research results into pre-service and especially in-service science teacher training. 


\section{ACKNOWLEDGEMENT}

The study initiated within the project "PROFILES: Professional Reflection-Oriented Focus on Inquiry-based Learning and Education though Science"(FP7SCIENCE-IN-SOCIETY-2010-1, 266589) and the project, Special Needs of Pupils in Context with Framework Educational Program for Primary Education“(MSM0021622443).

\section{REFERENCES}

Elliot, J., 1991. Action Research for Educational Change. 1st Edn., Open University Press, Philadelphia, ISBN-10: 0335096905, pp: 176.

Hammersley, M., 2002. Educational Research: Policymaking and Practice. 1st Edn., SAGE Publications Ltd., ISBN-10: 0761974199, pp: 180.

Hopkins, D., 2008. A Teacher's Guide to Classroom Research. 4th Edn., Open University Press, McGraw-Hill, Maidenhead, ISBN-10: 0335221750, pp: 240 .
Jarvinen, P., 2004. On Research Methods. 3rd Edn., Opinpajan Kirja Press, Tampere, Finland, ISBN-10: 9529923317, pp: 204.

Reeves, T.C., 2006. Design Research from the Technology Perspective. In: Educational Design Research, Akker, J.V., K. Gravemeijer, S. McKenney and N. Nieveen (Eds.), Taylor and Francis, London, ISBN-10: 0415396344, pp: 86109.

Siemens, G., 2005. Connectivism: A learning theory for the digital age. Int. J. Instructional Technol. Distance Learn., 2: 3-10.

Trna, J. and E. Trnova, 2010. ICT-based collaborative action research in science education. Proceedings of the 4th International Multi-Conference on Society, Cybernetics and Informatics, (SCI' 10), International Institute of Informatics and Systematics, Orlando, USA., pp: 68-70. 